\title{
INCIDENCE OF POSTOPERATIVE PAIN AFTER USING DIFFERENT KINEMATIC CUTTING MOTION IN MULTIPLE VERSUS SINGLE FILE CONCEPT
}

\author{
Weaam Anous*, Salma Al-Ashry ${ }^{* *}$, Magdy M. Ali ${ }^{* * *}$ and Mohamed Medhat Kataia ${ }^{* * * *}$
}

\begin{abstract}
Aim: Evaluate pain after using rotary instrument with different cutting motion and different number of instruments in vital mandibular teeth.

Materials and Methods: Thirty-two patient with vital mandibular first molar was selected for this study. The root canal treatment was done in single visit. The patients were asked to follow general instructions and to sign a printed informed consent that explains the aim of the study and obligates the patient to fill a pain diary before the treatment, after 3 hours after finishing of the treatment, 24 hours, 48 hours, 7 days. Root canals were mechanically prepared using the different techniques (8 vital teeth in each group). Group 1: The ProTaper Next files. Group 2: A primary reciprocating WaveOne Gold file. Group 3: A small reciprocating WaveOne Gold was used in reciprocating motion followed by primary reciprocating wave one gold file. Group 4: One shape rotary file. Obturation was carried out using the manufacture recommended gutta percha by selection of a master cone corresponding to the size of the master apical file. All canals were obturated using an epoxy resin-based sealer.
\end{abstract}

Results: Pre-operatively; there was no statistically significant difference between the four groups. Immediately post-operative; wave One gold (Primary) group showed the statistically significantly highest mean pain score. After 3 hours; wave One gold (Small and Primary) group showed the statistically significantly highest mean pain score. After 24 hours. 48 hours as well as 7 days; all groups showed no pain.

Conclusion: Reciprocating files showed more pain than rotation files.

Keywords: Rotary instrument, reciprocating instrument, postoperative pain.

\footnotetext{
* Assistant lecturer of endodontics, Faculty of Oral and Dental Medicine, Assiut University, Egypt.

** Professor of endodontics, Faculty of Oral and Dental Medicine, Ain Shams University, Egypt.

*** Professor of endodontics, Faculty of Oral and Dental Medicine, Beni Suef University, Egypt.

**** Associate professor and head of endodontic department, Faculty of Oral and Dental Medicine, British University,

Egypt.
} 


\section{INTRODUCTION}

The occurrence and control of pain are of critical interest in endodontic and, of particular importance, is the pain after root canal treatment. Post-endodontic pain was defined as pain of any degree that occurred after initiation of root canal treatment, whereas flare-up has been defined as the onset or continuation of pain and / or swelling after endodontic treatment ${ }^{(1)}$. The exact causes of pain following root canal treatment have not been adequately reported thus $\operatorname{far}^{(1-3)}$. Post endodontic pain is clearly multifactorial ${ }^{(4)}$, and one important cause has been claimed to be the instrumentation process ${ }^{(5)}$. Contemporary root canal preparation techniques employ the use of engine-driven nickeltitanium instruments that operate based on two kinematics - rotation or reciprocation. Therefore, it is mandatory to establish the influence of instrumentation technique on post treatment pain.

\section{MATERIALS AND METHODS}

Thirty-two patient were selected for this study. These patients were medically free. with age ranging between 25 to 45 years old with no sex predilection. Positive patient's acceptance for participating in the study was required. Vital mandibular first molar which shows early response with electric pulp tester was selected. The study was approved by the Committee of Research Ethics, Faculty of Oral and Dental Medicine, Minia University. After the explanation of the treatment procedure, the patients were asked to follow general instructions and to sign a printed informed consent that explains the aim of the study and obligates the patient to fill a pain diary before the treatment, after 3 hours after finishing of the treatment, 24 hours, 48 hours, 7 days.

Medical and dental histories were obtained by the dentist from all patients participating in this research in forms. These forms were obtained from Cohen's "Pathway of the Pulp"(6). Clinical and radiographic evaluations for each tooth included in this study were recorded. Prior to treatment, the operator recorded the tooth type, arch, patient's age and gender. The pulpal diagnosis for each tooth was based on the evaluation of the pre-operative pain status, clinical examination of the tooth, electric pulp tester, the patient's reaction to percussion, palpation. In addition, a periapical radiograph was taken, and periapical status was assessed. Also, periodontal evaluation was made clinically by periodontal probe. The root canal treatment was done in single visit. Before the commencement of intervention, the patient was asked to mark his/her level of pain on a visual analogue scale (VAS) for the "Before treatment" reading in the pain diary. Each patient was anesthetized by nerve block technique using a non-aspirating syringe with $1.8 \mathrm{ml}$ Mepivacaine $\mathrm{HCl}$ 2\%-Levonordefrin 1:20000. An access cavity preparation was performed using round bur size 2, and Endo-Z bur, tooth was disinfected using chlorhexidine mouth wash, and then the tooth was isolated using a rubber dam.

The patency of canals was made using hand $\mathrm{K}$-files size 10 and 15 , and the determination of working length was made by using electronic apex locator and was confirmed with intraoral periapical xray film $1 \mathrm{~mm}$ shorter than the apex. Root canals were mechanically prepared using the different techniques ( 8 vital teeth in each group)

Group 1: The ProTaper Next files were used in the sequence $\mathrm{X} 1$ with tip size 17 and taper 0.04 , $\mathrm{X} 2$ with tip size 25 and taper 0.06 , with a rotational speed of $300 \mathrm{rpm}$ and $200 \mathrm{~g} / \mathrm{cm}$ torque. Each file was used with a brushing motion away from the root concavities

Group 2: A primary reciprocating WaveOne Gold file with a tip size of 25 and a taper of 0.08 was used in a reciprocating, slow in-and-out pecking motion until reaching the full working length according to the manufacturer's instructions. The X-smart plus endo motor was used with the manufacturer's configuration setup.

Group 3: A small reciprocating WaveOne Gold with a tip size of 21 and a taper of 0.06 was 
used in reciprocating motion followed by primary reciprocating wave one gold file \#25.

Group 4: Oneshape rotary file \#25 taper 0.06 using a low torque motor at a constant speed of $400 \mathrm{rpm}$ and $400 \mathrm{~g} / \mathrm{cm}$ torque in pecking motions as recommended by the manufacturer.

A lubricant (glyde file prep) was used with each file. Working length was rechecked using the apex locator. All canals were irrigated using freshly-prepared $\mathrm{NaOCl}$ with a side vented needle A 27-gauge needle.

After the completion of preparation, the canals were dried using paper points. The details of each step will be recorded in the patient's clinical procedures sheet.

Obturation was carried out using the manufacture recommended gutta percha by selection of a master cone corresponding to the size of the master apical file. All canals were obturated using an epoxy resinbased sealer in which equal parts of the base and the catalyst of the sealer were mixed till obtaining a homogenous mix. Excess gutta percha was seared off using heated plugger. Pain was assessed immediately after obturation using VAS.

Numerical data were explored for normality by checking the distribution of data and using tests of normality (Kolmogorov-Smirnov and ShapiroWilk tests). Age data showed normal (parametric) distribution while pain scores showed non-normal (non-parametric) distribution. Data were presented as mean, standard deviation (SD), median and range values. For parametric data, one-way ANOVA test was used to compare between mean age values in the four groups. For non-parametric data; KruskalWallis test was used to compare between the four groups. Friedman's test was used to study the changes by time within each group. Dunn's test was used for pair-wise comparisons. The significance level was set at $\mathrm{P} \leq 0.05$.

\section{RESULTS}

\section{Demographic data:}

The mean and standard deviation for age were $\{29.6 \pm 2.5, \quad 30.3 \pm 4.8, \quad 30.8 \pm 4.9, \quad 30.2 \pm 3.2\}$ after using waveone gold (small and primary), waveone gold (primary), protaper next, one shape files respectively.

The frequencies and percentage for gender were in waveone gold (small and primary) [male:7(87.5\%), female:1(12.5\%)], waveone gold primary [male:6(75\%), female: $2(25 \%)$ ], protaper next [male:7(87.5\%), female:1(12.5\%)], and oneshape [ male:5(62.5\%), female:3(37.5\%)].

There was no statistically significant difference between mean age values in the four groups $(p=0.956)$. There was also no statistically significant difference between gender distributions in the four $\operatorname{groups}(\mathrm{p}=0.791)$.

\section{2- Pain scores}

\section{a. Comparison between the four groups (figure 1)}

Pre-operatively; the mean and standard deviation of pain scores were $90 \pm 10.7,83.8 \pm 13$, $82.5 \pm 15.8,76.3 \pm 13$ for waveone gold (small and primary), wave one gold primary, protaper next, one shape respectively. There was no statistically significant difference between the four groups $(p$-value $=0.179$, effect size $=0.068)$.

Immediately post-operative; there was a statistically significant difference between the four groups $(p$-value $=0.004$, effect size $=0.367)$. Pairwise comparisons between the groups revealed that wave One gold (Primary) group showed the statistically significantly highest mean pain score $[5 \pm 5.3]$. There was no statistically significant difference between Wave One gold (Small and Primary), ProTaper Next and One Shape groups; all showed the statistically significantly lowest median pain scores $[0 \pm 0)]$. 


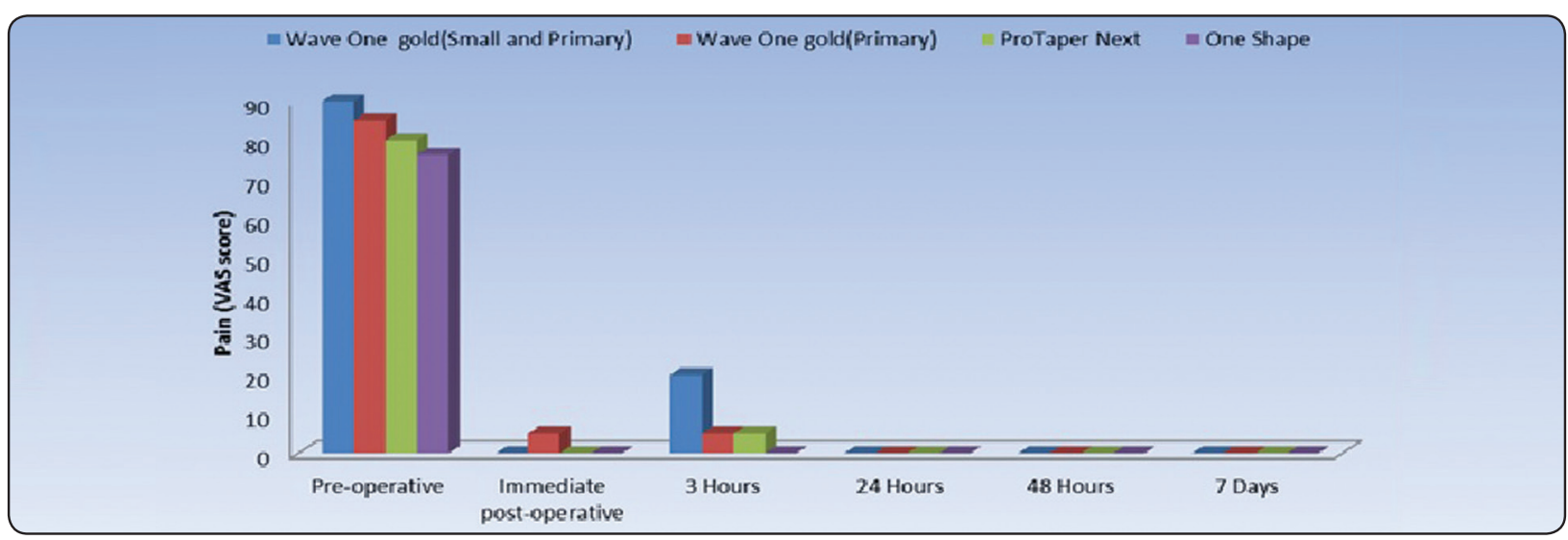

Fig. (1) Bar chart representing median values for pain scores in vital teeth of the four groups.

After 3 hours; there was a statistically significant difference between the four groups ( $p$-value $<0.001$, effect size $=0.683)$. Pair-wise comparisons between the groups revealed that wave One gold (Small and Primary) group showed the statistically significantly highest mean pain score [20 \pm 10.7$]$. There was no statistically significant difference between Wave One gold (Primary)and ProTaper Next groups; both showed statistically significantly lower mean pain scores [5 5 5.3]. One Shape group showed the statistically significantly lowest mean pain score [zero].

After 24 hours. 48 hours as well as 7 days; all groups showed no pain with mean and standard deviation of $[0 \pm 0]$.

\section{b. Changes by time within each group (Figure 2)}

\section{Wave One gold (Small and Primary)}

There was a statistically significant change by time in pain scores in Wave One gold (Small and Primary) group $(P$-value $<0.001$, Effect size $=$ 1.000).

Pair-wise comparisons between the time periods revealed that there was a statistically significant decrease in pain scores immediately postoperatively with mean and standard deviation of $[0 \pm 0]$ followed by a statistically significant increase in pain scores after 3 hours with mean and standard deviation of [ $20 \pm 10.7]$. From 3 to 24 hours, there was a statistically significant decrease in pain scores with mean and standard deviation $[0 \pm 0]$ followed

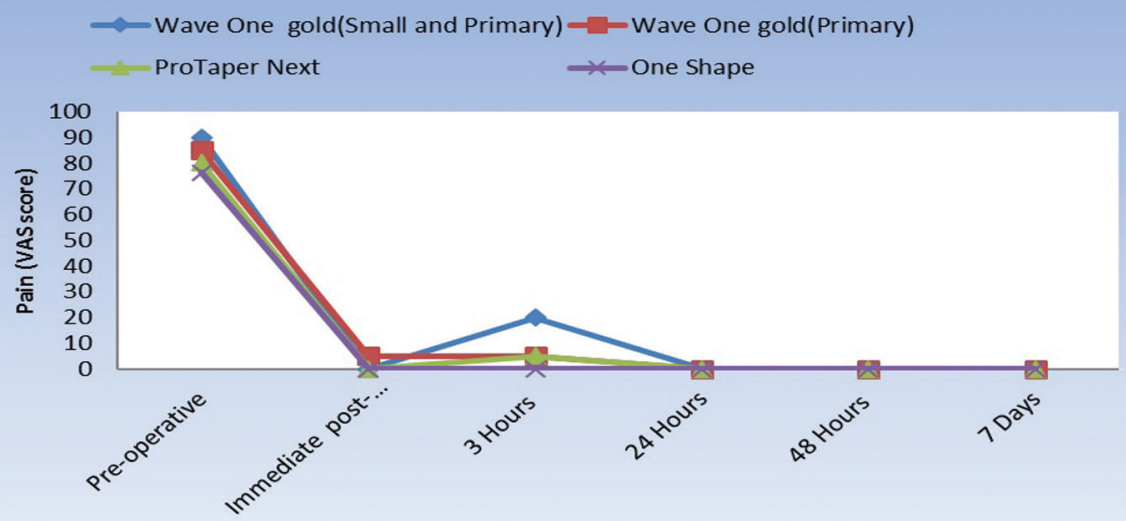

Fig. (2) Line chart representing change by time in pain scores within each group 
by non-statistically significant change from 24 to 48 hours with mean and standard deviation $[0 \pm 0]$ as well as from 48 hours to 7 days with mean and standard deviation $[0 \pm 0]$.

\section{Wave One gold (Primary)}

There was a statistically significant change by time in pain scores in Wave One gold (Primary) group $(P$-value $<0.001$, Effect size $=0.750)$.

Pair-wise comparisons between the time periods revealed that there was a statistically significant decrease in pain scores immediately post-operatively with mean and standard deviation [5 5.3.3 followed by non- statistically significant change in pain scores after 3 hours with mean and standard deviation [5 $5 \pm 5.3]$.

From 3 to 24 hours, there was a statistically significant decrease in pain scores with mean and standard deviation [0 $0 \pm 0]$ followed by nonstatistically significant change from 24 to 48 hours with mean and standard deviation $[0 \pm 0]$ as well as from 48 hours to 7 days with mean and standard deviation $[0 \pm 0]$.

\section{ProTaper Next}

There was a statistically significant change by time in pain scores in ProTaper Next group $(P$-value $<0.001$, Effect size $=0.875$ ) .

Pair-wise comparisons between the time periods revealed that there was a statistically significant decrease in pain scores immediately post-operatively with mean and standard deviation $[0 \pm 0]$ followed by a statistically significant increase in pain scores after 3 hours with mean and standard deviation [5 55.3$]$.

From 3 to 24 hours, there was a statistically significant decrease in pain scores with mean and standard deviation [0 $0 \pm 0]$ followed by nonstatistically significant change from 24 to 48 hours with mean and standard deviation $[0 \pm 0]$ as well as from 48 hours to 7 days with mean and standard deviation $[0 \pm 0]$.

\section{One Shape}

There was a statistically significant change by time in pain scores in One Shape group ( $P$-value $<0.001$, Effect size $=1.000$ ).

Pair-wise comparisons between the time periods revealed that there was a statistically significant decrease in pain scores immediately post-operatively

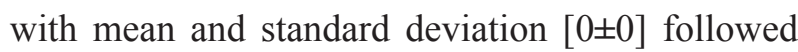
by non-statistically significant change in pain scores after 3 hours to 48 hours as well as from 48 hours to 7 days with mean and standard deviation $[0 \pm 0]$.

\section{DISCUSSION}

Postoperative pain is a common complication after root canal treatment, which severely affects patients. Postoperative pain may occur for a variety of reasons, including preparation beyond the apical terminus, incomplete removal of pulp tissue, overextension of root canal filling material, and extrusion of dentinal and pulpal debris into the periapical area (Seltzer \& Naidorf ${ }^{(7)}$, Shokraneh et al $\left.{ }^{(8)}\right)$. The instrumentation used for this procedure has been demonstrated to be an important operatordependent factor that affects the incidence and intensity of postoperative pain. So, in this study we compared the difference between rotation and reciprocation on postoperative pain.

The type of the tooth was standardized by selecting only mandibular molar teeth since they were more associated with greater susceptibility to post-operative pain ${ }^{(9)}$. This may be due to canal system complexity rendering debridement more difficult or simply of higher number of roots and canal exists, increasing risk of post-operative complication $^{(10,11)}$.

It is well-known that pain perception is a highly subjective and variable experience which is affected by multiple physical and psychological factors ${ }^{(12)}$. It is difficult to objectively measure a patient's level of discomfort; data for this variable therefore depend on subjective information provided by the patients 
themselves and are subject to error ${ }^{(13)}$. Different scales have been used to assess pain after endodontic treatment as modified Heft-Parker VAS which were ranged as $(0-170)^{(14)}$, VAS $(0-5)^{(15-17)}$, VAS $(0-10)^{(18)}$, VAS (0-100) ${ }^{(11,19)}$ and also pain might be recorded as (none, slight, moderate, severe) ${ }^{(20,21)}$. In this study we used modified VAS (0-100) to evaluate pain as a result of its valid and reliable ratio scale to measure pain ${ }^{(22)}$, also pain has been explained visually and verbally ${ }^{(23)}$ for better understanding by the patients.

Assessment of pain intensity was done using VAS, immediately, 3hours, 24 hours, 48 hours and 7 days after obturation. These intervals were chosen as 3 hours post-operatively was considered enough time to allow anaesthetic-solution effect to completely disappear ${ }^{(24,25)}$.

However, 24 hours was chosen as postoperative pain that generally develops due to the acute inflammatory response in the periapical tissues that begins within a few hours or days after root canal instrumentation (Neelakantan \& Sharma) ${ }^{(26)}$.

For 48 hours, time period was selected to evaluate postoperative pain, since the prevalence and severity of pain substantially decrease within the first 2 day ${ }^{(27)}$. The 7 days interval was chosen as most previous studies used this time interval to assess post-operative pain ${ }^{(28,29)}$.

Irrigation was done by household bleach brand (Clorox) using a side vented needle as this needle cause less apical extrusion of irrigant when compared with regular irrigating needle ${ }^{(30)}$. Needle was adjusted $3 \mathrm{~mm}$ shorter than working length by using rubber stopper ${ }^{(31)}$ as it was revealed that deep penetration of irrigating solution into the root canals results in more effective removal of debris and allow adequate irrigant exchange ${ }^{(32)}$ but also lead to increase mean pressure at the apical foramen, indicating an increase risk of irrigant extrusion toward the periapical tissue. So as a compromise, irrigating needles were not used to the full working length but $3 \mathrm{~mm}$ shorter than the working length.
The resin-based epoxy sealer AH plus was used in obturation as it has an acceptable physical property, apical seal ability, low solubility, microretention to root dentin ${ }^{(33,34)}$ and had the highest bond to dentin with or without smear layer removal ${ }^{(35)}$.

The instrument systems used in this study were based on a close match in terms of tip size of the instruments to maintain standardization and to rule out the effect of varying tip diameters on postoperative pain ${ }^{(36)}$.

Single-visit endodontic treatment was chosen to maintain a simple uniform treatment protocol and to rule out the potential influence of intracanal medication. Also, because a meta-analysis showed that patients undergoing one-visit root canal therapy exhibited significantly less endodontic postoperative pain compared with those undergoing a two-visit treatment protocol ${ }^{(37)}$.

In the current study in the vital teeth, wave one gold primary shows immediately postoperative pain more than the other groups as the postoperative pain intensity may be related to the root canal preparation system. Since it is a big single-file of increased taper, which directly reach the apex. In many cases, in order to reach the apical working length, reciprocating instruments are used with force directed apically, which makes an effective piston to propel debris from a patent apical foramen. Since instruments are used without any preliminar coronal enlargement, a greater engagement of flutes and, consequently, more torque or pressure are applied. More over cutting ability of a reciprocating file is smaller when compared to a continuous rotation, and also debris removal is smaller, thus increasing the frictional stress and torque demand, due to entrapment of debris within the flutes ${ }^{(38)}$. A meta-analysis evaluating laboratory studies demonstrated that the reciprocating movement leads to greater debris extrusion in comparison with the continuous rotary movement (Caviedes-Bucheli et al) ${ }^{(39)}$, which could trigger a greater inflammatory response and, consequently, a greater pain process. 
This is in agreement with (El Mubarak et al ${ }^{(40)}$, Cruz Júnior et al $\left.{ }^{(41)}\right)$. This is in disagreement with Saha

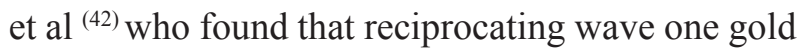
file showed lesser postoperative pain than rotating protaper next file.

After 3 hours wave one (small and primary) shows more pain than the other groups, which might be attributed to the expression of pro-inflammatory mediators and neuropeptides such as substance $P$ and calcitonin gene-related peptide in the periodontal ligament subsequent to root canal preparation. This is in agreement with other studies which showed increase pain during the first 6 hours $^{(43,44)}$.

The incidence of PP was lower in patients treated with rotary instruments than reciprocating instruments, perhaps because rotary instruments reduce debris extrusion, which decreases the irritation and minimizes inflammation and the release of chemical substances ${ }^{(45)}$. This is in agreement with other study which showed that reciprocating systems can cause greater debris extrusion ${ }^{(46)}$, or accumulation of debris in the root canal ${ }^{(47)}$ than rotary systems, possibly as a result of the reverse motion of the reciprocating instrument. This is in disagreement with other study which stated that less apical extrusion of bacteria was produced using the reciprocating system ${ }^{(48)}$.

In the wave one gold file (small and primary) and protaper next file there was a significant change by time in the pain scores where pain decreases immediately after the treatment which might be due to the effect of the anesthesia and then increases at 3 hours which might be attributed to the expression of pro-inflammatory mediators and neuropeptides such as substance $\mathrm{P}$ and calcitonin gene-related peptide in the periodontal ligament subsequent to root canal preparation ${ }^{(43,44)}$. and also due to the wearing off the local anesthetic effect and then decerased till the 7 days and this is in accordance with other studies who stated that if post endodontic pain is present lasts $<72 \mathrm{hrs}^{(49)}$
In waveone gold file (primary) and one shape there was a statically significant decrease in pain in all time period and this is in agreement with other studies which showed that postoperative pain prevalence decline sharply particularly over the first two days and continue to decrease till one week (Pak and White ${ }^{(4)}$, Pasqualini et al ${ }^{(50)}$ ).

However, the difficulty of standardizing patient reports of pain following treatment due to the complexity of the individual response and the variety of measures used to quantify the painful experience must be appreciated (Dugas et al ${ }^{(51)}$ )

\section{REFERENCES}

1. Walton R, Fouad A. Endodontic interappointment flareups: a prospective study of incidence and related factors. $\mathrm{J}$ Endod 1992;18: 172- 7 .

2. Georgopoulou M, Anastassiadis P, Sykaras S. Pain after chemomechanical preparation. Int Endod J 1986; 19(6):309-314

3. Negm MM. Management of endodontic pain with nonsteroidal anti-inflammatory agents: a double-blind, placebo-controlled study. Oral Surg Oral Med Oral Pathol 1989; 67(1):88-95

4. Pak JG, White SN. Pain prevalence and severity before, during, and after root canal treatment: a systematic review. J Endod 201137(4):429-438.

5. Harrington GW, Natkin E. Midtreatment flare-ups. Dent ClinN Am 1992;36(2):409-423

6. Berman LH and Hartwell GR. Diagnosis. In: Cohen S, Hargreaves KM, eds. Pathway of the pulp, 9th edition. St. Louis, MO: Mosby; 2005: 5-7.

7. Seltzer $\mathrm{S}$ and Naidorf IJ. Flare-ups in endodontics: I. Etiological factors. J Endod 1985; 11: 472-478

8. Shokraneh A, Ajami M, Farhadi N, Hosseini M and Rohani B. Postoperative endodontic pain of three different instrumentation techniques in asymptomatic necrotic mandibular molars with periapical lesion: a prospective, randomized, double-blind clinical trial. Clinical oral investigations 2017; 21: 413-418

9. Eleazer PD and Eleazer KR. Flare-up rate in pulpally necrotic molars in one-visit versus two-visit endodontic treatment. J Endod 1998; 24: 614-616.

10. Alacam $\mathrm{T}$ and Tinaz AC.Interappoitment emergencies in teeth with necrotic pulps. J Endod 2002; 28: 375-377. 
11. Ehrmann EH, Messer HH, Adams GG. The relationship of intracanal medicaments to postoperative pain in endodontics. Int Endod J 2003; 36: 868-875.

12. Bender IB. Pulpal pain diagnosis: a review. J Endod 2000; 26: $175-9$.

13. Almeida G, Marques E, De Martin AS, Bueno CE, Nowakowski A, Cunha RS. Influence of irrigating solution on postoperative pain following single-visit endodontic treatment: A randomized clinical trial. J Can Dent Assoc 2012; 78: 84-89

14. Direnzo A, Gresla T, Johnson BR, Rogers M, Tucker D, BeGole EA. Postoperative pain after 1- and 2-visit root canal therapy. Oral Surg Oral Med Oral Pathol Oral Radiol Endod. 2002; 93: 605-10

15. Glennon JP, Ng Y-L, Setchell DJ, Gulabivala K. Prevalence of and factors affecting postpreparation pain in patients undergoing two-visit root canal treatment. Int Endod J. 2004; 37: 29-37.

16. Ng Y-L, Glennon JP, Setchell DJ, Gulabivala K. Prevalence of and factors affecting post-obturation pain in patients undergoing root canal treatment. Int Endod J. 2004; 37: 381-391.

17. Risso PA, Cunha AJLA, Araujo MCP, Luiz RR. Postoperative pain and associated factors in adolescent patients undergoing one- and twovisit root canal treatment. J Dent. 2008; 36: 928-934.

18. Segura- Egea JJ, Cisneros-Cabello R, Llamas-Carreras JM, Velas Ortega E. Pain associated with root canal treatment. Int Endod J. 2009; 42: 614-620.

19. Mattscheck DJ, Law AS, Noblett WC. Retreatment versus initial root canal treatment: Factors affecting posttreatment pain. Oral Surg Oral Med Oral Pathol Oral Radiol Endod. 2001; 92: 321-4

20. Yoldas O, Topuz A, Isçi S, Oztunc H. Postoperative pain after endodontic retreatment: Single- versus two-visit treatment. Oral Surg Oral Med Oral Pathol Oral Radiol Endod. 2004; 98: 483-7.

21. Oginni AO and Udoye CI. Endodontic flare-ups: comparison of incidence between single and multiple visit procedure in patients attending a Nigerian teaching hospital. BMC Oral Health. 2004; 4: 4

22. Al-Negrish AR, Habahbeh R. Flare up rate related to root canal treatment of asymptomatic pulpally necrotic central incisor teeth in patients attending a military hospital. J Dent. 2006; 34: 635-40.

23. Jalalzadeh SM, Mamaui A, Sbabriari S, Santos FA, Pocbapski M. Effect of pretreatment prednisolone on postendodontic pain: A doubleblind parallel-randomized clinical trial. J Endod. 2010; 36: 978-981.

24. Yagiela JA. Local anesthetics. In: Yagiela JA, Neidle EA, Dowd FJ, editors. Pharmacology and therapeutics for dentistry. 4th ed. St. Louis: Mosby; 1998: 217-34.

25. Yagiela JA. Local anesthetics. In: Dionne RA, Phero JC, Becker DE, editors. Pain and anxiety control in dentistry. Phiadelphia: W.B. Saunders; 2002: 78-96.

26. Neelakantan P, Sharma S. Pain after single-visit root canal treatment with two single-file systems based on different kinematics--a prospective randomized multicenter clinical study. Clin Oral Investig 2015; 19(9):2211-7.

27. Seltzer S. Pain in endodontics. 1986. J Endod. 2004; 30: 501-3

28. Torabinejad M, Shabahang S, Bahjri K. Effect of MTAD on postoperative discomfort: a randomized clinical trial. J Endod 2005; 31: 171-176

29. Bashetty $\mathrm{K}$ and Hegde J. Comparison of $2 \%$ chlorhexidine and $5.25 \%$ sodium hypochlorite irrigating solutions on postoperative pain: A randomized clinical trial. Indian J Dent Res. 2010; 21: 523-7.

30. Altundasar E, Nagas E, Uyanik O, Serper A. Debris and irrigant extrusion potential of two rotary systems and irrigation needles. Oral Surg Oral Med Oral Pathol Oral Radiol Endod. 2011; 112: e31-e35.

31. Boutsioukis C, Verbaagen B, Versluis M, Kastrinakis E, Wesselink PR, Sluis LW. Evaluation of irrigant flow in the root canal using different needle types by an unsteady computational fluid dynamics model. J Endod. 2010; 36: 875-879.

32. Boutsioukis C, Lambrianidis T, Ver Laagen B, Versluis M, Eleftherios Kartrinakis E, Wesselink P, Vander Sluis L. The effect of needle-insertion depth on the irrigant flow in the root canal: Evaluation using an unsteady computational fluid dynamics model. J Endod. 2010; 36: 1664-1668.

33. Altundasar E, Nagas E, Uyanik O, Serper A. Debris and irrigant extrusion potential of two rotary systems and irrigation needles. Oral Surg Oral Med Oral Pathol Oral Radiol Endod. 2011; 112: e31-e35.

34. Boutsioukis C, Verbaagen B, Versluis M, Kastrinakis E, Wesselink PR, Sluis LW. Evaluation of irrigant flow in the root canal using different needle types by an unsteady computational fluid dynamics model. J Endod. 2010; 36: 875-879.

35. Boutsioukis C, Lambrianidis T, Ver Laagen B, Versluis M, Eleftherios Kartrinakis E, Wesselink P, Vander Sluis L. 
The effect of needle-insertion depth on the irrigant flow in the root canal: Evaluation using an unsteady computational fluid dynamics model. J Endod. 2010; 36: 1664-1668.

36. Kherlakian D, Cunha RS, Ehrhardt IC, Zuolo ML, Kishen A, da Silveira Bueno CE. Comparison of the Incidence of Postoperative Pain after Using 2 Reciprocating Systems and a Continuous Rotary System: A Prospective Randomized Clinical Trial. J Endod 2016;42(2):171-6.

37. Su Y, Wang C,Ye L. healing rate and post-obturation pain of single- versus multiple-visit endodontic treatment for infected root canals: a systematic review. J Endod. 2011; 37(2):125-32.

38. De-Deus G, Barino B, Zamolyi RQ, Souza E, Fonseca A Jr, Fidel S, Fidel RA. Suboptimal debridement quality produced by the single-file F2 ProTaper technique in ovalshaped canals. J Endod. 2010; 36:1897-900.

39. Caviedes-Bucheli J, Castellanos F, Vasquez N, Ulate E, Munoz HR. The influence of two reciprocating singlefile and two rotary-file systems on thee apical extrusion of debris and its biological relationship with symptomatic apical periodontitis. A systematic review and metaanalysis. Int Endod J. 2015; 49:255-70.

40. El Mubarak AH, Abu-bakr NH, Ibrahim YE. Postoperative pain in multiple-visit and single-visit root canal treatment. J Endod. 2010; 36: 36-9.

41. Cruz Junior JA,Coelho MS, Kato AS. The effect of foraminal enlargement of necrotic teeth with the reciproc system on postoperative pain: a prospective and randomized clinical trial. J Endod. 2016; 42: 8-11.

42. Saha SG, Gupta RK, Bhardwaj A, Misuriya A, Saha MK, Nirwan AS. Comparison of the incidence of postoperative pain after using a continuous rotary system, a reciprocating system, and a Self-Adjusting File system in single-visit endodontics: A prospective randomized clinical trial. J Conserv Dent 2018; 21:333-8
43. Nekoofar MH, Sheykhrezae MS, Meraji N, Jamee A, Shirvani A, Jamee J, Dummer PM. Comparison of the effect of root canal preparation by using WaveOne and ProTaper on postoperative pain: a randomized clinical trial. J Endod 2015;41(5):575-8.

44. Krithikadatta J, Sekar V, Sudharsan P, Velumurugan $\mathrm{N}$. Influence of three $\mathrm{Ni}-\mathrm{Ti}$ cleaning and shaping files on postinstrumentation endodontic pain: A tripleblinded, randomized, controlled trial. J Conserv Dent 2016;19(4):311-6.

45. Torabinejad M, Cotti E, Jung T. Concentrations of leukotriene B4 in symptomatic and asymptomatic periapical lesions. J Endod. 1992; 18: 205-8.

46. Burklein S, Schafer E. Apically extruded debris with reciprocating single-file and full-sequence rotary instrumentation systems. J Endod. 2012; 38: 850-2.

47. Robinson JP, Lumley PJ, Cooper PR, Grover LM, Walmsley AD. Reciprocating root canal technique induces greater debris accumulation than a continuous rotary technique as assessed by 3-dimensional micro-computed tomography. J Endod. 2013; 39: 1067-70

48. Tinoco JM, De-Deus G, Tinoco EM, Saavedra F, Fidel RA, Sassone LM. Apical extrusion of bacteria when using reciprocating single-file and rotary multifile instrumentation systems. Int Endod J. 2014; 47: 560-6

49. Marshall JG. Consideration of steroids for endodontic pain. Endod Topics 2002; 3: 41-51.

50. Pasqualini D, Mollo L, Scotti N et al. Postoperative pain after manual and mechanical glide path: a random-ized clinical trial. J Endod. 2012; 38: 32-6.

51. Dugas NN, Lawrence HP, Teplitsky P, Friedman S. Quality of life and satisfaction outcomes of endodontic treatment. J Endod. 2002; 28:819-27. 